\title{
Retinal Changes In Patients with Hepatitis C Virus under treatment with interferon and ribavirin.
}

\author{
Dr. Mansour Hassan Ahmad Hassan ${ }^{a}$, Dr. Mohamed Osman ${ }^{a}$, Dr. Waleed El-Nabawy ${ }^{b}$ and \\ Dr. Alzahraa Yasseen Sayed ${ }^{a}$ \\ ${ }^{a}$ Ophthalmology department, Faculty of Medicine, Beni-Suef University, Egypt \\ ${ }^{\mathrm{b}}$ Internal medicine department, Faculty of Medicine, Beni-Suef University, Egypt
}

\begin{abstract}
Background: Chronic Hepatitis C is common problem worldwide treated by combination of interferon alpha and ribavirin. Retinopathy is one of the side effects of interferon therapy. Aim: determine the frequency and risk factors of retinopathy in patients with chronic hepatitis $\mathrm{C}$ treated by interferon and ribavirin combination therapy in Egypt. Methods and Results: Total 100 patients were enrolled among which, 16 (16\%) developed retinopathy in the form of cotton wool spots and 14(14\%) developed atypical complications. Conclusion: Retinopathy may occur in patients with chronic hepatitis $\mathrm{C}$ receiving interferon alpha and ribavirin.
\end{abstract}

\section{Keywords}

Retinopathy, Interferon, ribavirin, chronic hepatitis C.

\section{Introduction}

Interferons (IFNs) are glycoproteins made and released by host cells in response to the presence of pathogens, such as viruses, bacteria, parasites, or tumor cells. In a typical scenario, a virus-infected cell will release IFNs causing nearby cells to ramp up their anti-viral defenses [1].

IFNs belong to the large class of proteins known as cytokines; molecules used for communication between cells to trigger the protective defenses of the immune system that help eradicate pathogens. Interferons are named for their ability to "interfere" with viral replication by protecting cells from virus infection [2]. IFNs also have other functions: they activate immune cells, such as natural killer cells and macrophages; they increase host defenses by up-regulating antigen presentation by virtue of increasing the expression of major histocompatibility complex (MHC) antigens [3]. 
Certain symptoms of infections, such as fever, muscle pain and "flu-like symptoms" are also caused by the production of IFNs and other cytokines [4].

More than twenty distinct IFN genes and proteins have been identified in animals, including humans. They are typically divided among three classes: Type I IFN, Type II IFN, and Type III IFN. IFNs belonging to all three classes are important for fighting viral infections and for the regulation of the immune system. [5].

Hepatitis C is treated with IFN- $\alpha$, often in combination with other antiviral drugs [6]. Some of those treated with interferon have a sustained virological response and can eliminate hepatitis virus. The most harmful strain - hepatitis C genotype I virus - can be treated with a $60-80 \%$ success rate with the current standard - of -care treatment of interferon- $\alpha$, ribavirin and recently approved protease inhibitors such as Telaprevir (Incivek) May 2011, Boceprevir (Victrelis) May 2011 or the nucleotide analog polymerase inhibitor Sofosbuvir (Sovaldi) December 2013[7].

Biopsies of patients, given the treatment, show reductions in liver damage and cirrhosis. Some evidence shows giving interferon immediately following infection can prevent chronic hepatitis $\mathrm{C}$, although diagnosis early in infection is difficult since physical symptoms are sparse in early hepatitis $\mathrm{C}$ infection. Control of chronic hepatitis $\mathrm{C}$ by IFN is associated with reduced hepatocellular carcinoma [8].

However, IFN therapy often is associated with ocular side effects. Although most resolve while treatment continues and are asymptomatic, severe ocular complications can occur, including branch vein occlusion, retinal rubeosis and cystoid macular edema, It is defined IFN-induced retinopathy if patients had retinal hemorrhage, cotton-wool spots, or both during IFN treatment. No patient with diabetes had retinopathy before IFN treatment [9].

\section{Patients and Methods}

All chronic hepatitis C patients (100 patients) were selected from, Beni Suef general hospital Viral Hepatitis unit. Patients aged from 20 to 60 years with positive HCV by Polymerase Chain Reaction were included. Full ocular examination was performed before start of treatment and at weeks $2,4,8,16$, and 24 after the start of IFN and ribavirin administration.

\subsection{Inclusion criteria:}

Any patient male or female, 20-60 years old, having chronic hepatitis $\mathrm{C}$ virus infection and treated with interferon alpha (Reiferon Retard) and ribavirin combination therapy.

\section{Exclusion criteria:}

Patients with evidence of D.M, hypertension decompensated liver disease and patients known to have retinal vascular disease before starting interferon therapy were excluded from our study. 


\subsection{All patients were subjected to:}

Precise personal and medical history were taken from all of the patients .All patients were weighed and underwent a baseline ophthalmic ,liver, and full laboratory assessment evaluation before starting interferon treatment. In addition the systemic blood pressure was measured. Total hundred patients who fulfilled the criteria were included in this study. Ophthalmic examination was repeated, before and at weeks $2,4,8,16$, and 24 after the start of IFN and ribavirin administration.

\section{- Ophthalmological assessment} Bilateral

- Pupil examination.

- Best corrected visual acuity (BCVA) using Snellen's chart.

- Slit lamp bimicroscopy examination.

- Intraocular pressure with applanation tonometer.

- Post dilation binocular indirect ophthalmoscopy, (Fundoscopy) using+20 D lens.

- Assessment of posterior pole using +90 D (Bimicroscopy).

- Colored fundus photographs and fundus fluorescein angiography were documented for comparison, when retinal abnormalities and ischemic retinopathy were detected. Examination was performed by wearing sterile gloves to eliminate the risk of infection via the tear film.

\section{Statistical methodology}

Data were statistically described in terms of mean \pm standard deviation $( \pm S D)$, median and range, or frequencies (number of cases) and percentages when appropriate. Comparison of numerical variables between the study groups was done using Student $t$ test for independent samples. For comparing categorical data, Chi square $\left(\chi^{2}\right)$ test was performed. Exact test was used instead when the expected frequency is less than 5. $P$ values less than 0.05 was considered statistically significant. All statistical calculations were done using computer programs SPSS (Statistical Package for the Social Science; SPSS Inc., Chicago, IL, USA) version 15 for Microsoft Windows.

\section{Results}

A total of hundred patients were enrolled in our study which has been conducted in ophthalmology department, from may 2015 till April 2016. Patients were selected from Beni Suef viral hepatitis unit from Beni Suef general hospital.

\section{- Interferon related complications}

From total 100 patients, 46 eyes (23\%) of 30 patients $(30 \%)$ were affected, between the $12^{\text {th }}$ and $24^{\text {th }}$ week of therapy. 
Age: The most affected age group was between 41-50 years old, represented in 16 patients $(53 \%)$. The age factor was statistically significant with $p$ value 0.041(less than 0.05) (Table 1)

Table 1. Age groups, its percentage and significance in interferon related complications group

\begin{tabular}{|c|c|c|c|c|c|}
\hline & & & $\begin{array}{l}\text { Interfer } \\
\text { complic }\end{array}$ & ions & Total \\
\hline & & & No & Yes & \\
\hline Age-G & $20-30 y s$ & Count & 16 & 2 & 18 \\
\hline & & $\%$ within complications & $22.8 \%$ & $6.6 \%$ & $18.0 \%$ \\
\hline & $31-40 y s$ & Count & 24 & 4 & 28 \\
\hline & & $\%$ within complications & $34.2 \%$ & $13.3 \%$ & $28.0 \%$ \\
\hline & $41-50 y s$ & Count & 26 & 16 & 42 \\
\hline & & $\%$ within complications & $37.1 \%$ & $53.3 \%$ & $42.0 \%$ \\
\hline & $51-60 y s$ & Count & 4 & 8 & 12 \\
\hline & & $\%$ within complications & $5.7 \%$ & $26.6 \%$ & $12.0 \%$ \\
\hline Total & & Count & 70 & 30 & 100 \\
\hline & & $\%$ within complications & $100.0 \%$ & $100.0 \%$ & $100.0 \%$ \\
\hline Pvalue & $<0.05$ & & 0.041 & & \\
\hline
\end{tabular}

Sex: The patient's gender was statistically insignificant to interferon related complications (Table 2).

Table 2.Gender and significance in interferon related complications group

\begin{tabular}{|c|c|c|c|c|c|}
\hline & & \multicolumn{2}{|c|}{$\begin{array}{l}\text { Interferon } \\
\text { complications }\end{array}$} & \multirow[t]{2}{*}{ Total } \\
\hline & & & $\mathrm{No}$ & Yes & \\
\hline \multirow{4}{*}{ Sex } & \multirow[b]{2}{*}{ Males } & Count & 52 & 18 & 70 \\
\hline & & $\begin{array}{l}\text { \% within } \\
\text { complications }\end{array}$ & $74.2 \%$ & $60.0 \%$ & $70.0 \%$ \\
\hline & \multirow[b]{2}{*}{ Females } & Count & 18 & 12 & 30 \\
\hline & & $\begin{array}{l}\% \text { within } \\
\text { complications }\end{array}$ & $25.7 \%$ & $40.0 \%$ & $30.0 \%$ \\
\hline \multirow{2}{*}{\multicolumn{2}{|c|}{ Total }} & Count & 70 & 30 & 100 \\
\hline & & $\begin{array}{l}\% \quad \text { within } \\
\text { complications }\end{array}$ & $100.0 \%$ & $100.0 \%$ & $100.0 \%$ \\
\hline$p$ value & $>0.05$ & & \multicolumn{2}{|l|}{0.514} & \\
\hline
\end{tabular}




\section{- Types of complications}

Complications include, Cotton wool spots in $16 \%$, maculopathy in $8 \%$, disc edema in $2 \%$, glaucomatous cupping in $2 \%$ and posterior vitreous detachment in 2\% (Figure 2-6)

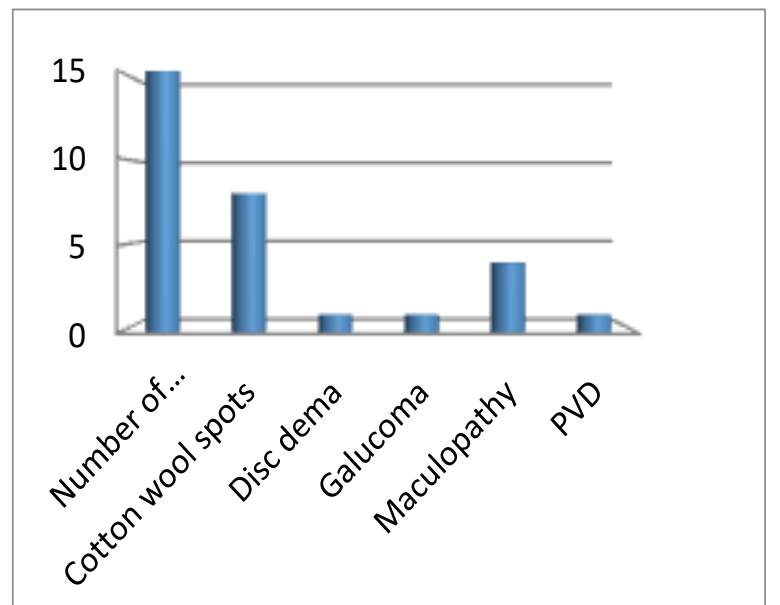

Figure 2-6.Type of interferon related complication

\section{- Cotton wool spots (IFN-retinopathy) :}

Twenty two eyes (11\%), in 16 patients $(16 \%)$,developed interferon retinopathy in the posterior pole around the optic disc in the form of cotton wool spots; in all patients the macular area was unaffected (Figure 3-6).

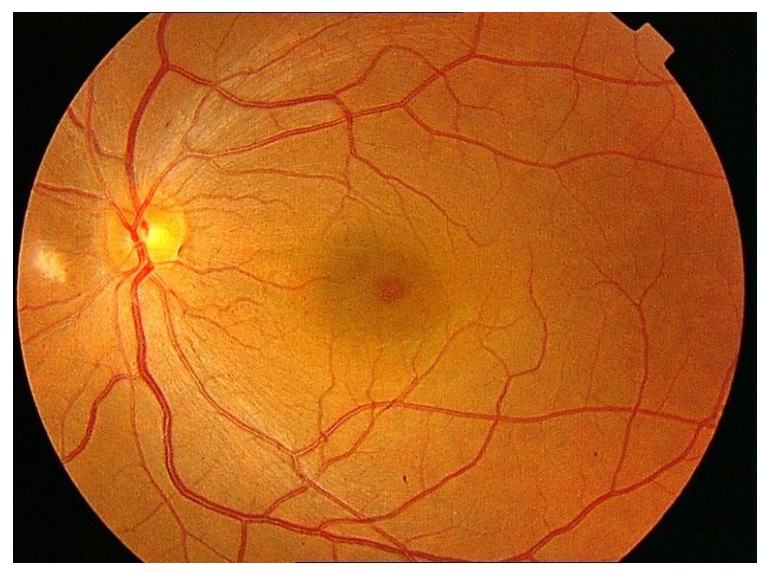

Figure 3-6. Colored fundus photography of the left eye showing cotton wool spot

The age ranged from 33 to 60 years old with mean \pm SD of $46.7 \pm 7.8$ (Figure 4-6). The age was statistically significant with a $p$ value of 0.041 (less than 0.05).

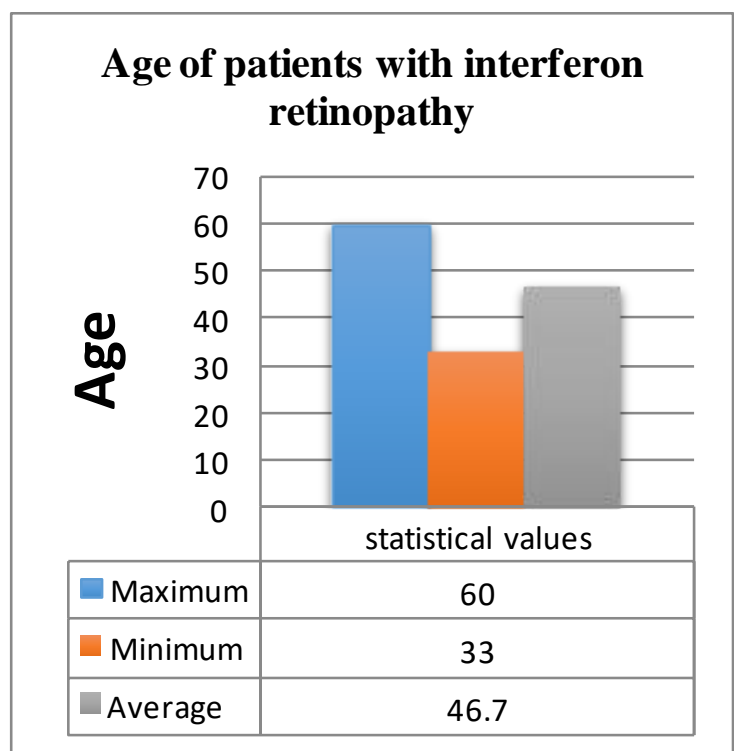

Figure 4-6. Bar chart showing the age group of patients with cotton wool spots

Ten out of the sixteen patients developed unilateral cotton wool spots $(10 \%)$ and six $(6 \%)$ developed bilateral cotton wool spots. Ten patients $(10 \%)$ were males and six $(6 \%)$ were females (Figure 5-6)

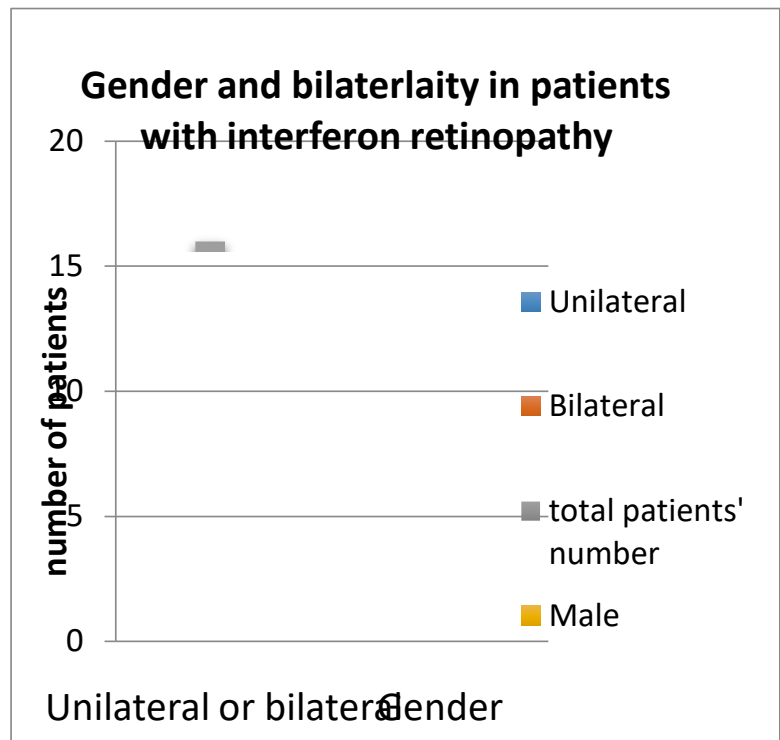

Figure 5-6.Gender and bilaterality in patients with cotton wool spots

Two patients (2\%) out of twelve having low hemoglobin level developed cotton wool spot in the left eye.Six patients (6\%), from this group 
didn't have diabetes or hypertension or any comorbid illness.

\section{- Disc edema :}

One male patient (1\%)30 years old without any co-morbid illness, presented with bilateral hyperemic discs and blurred edges in the first 12 weeks of interferon therapy(Figure 8-6).

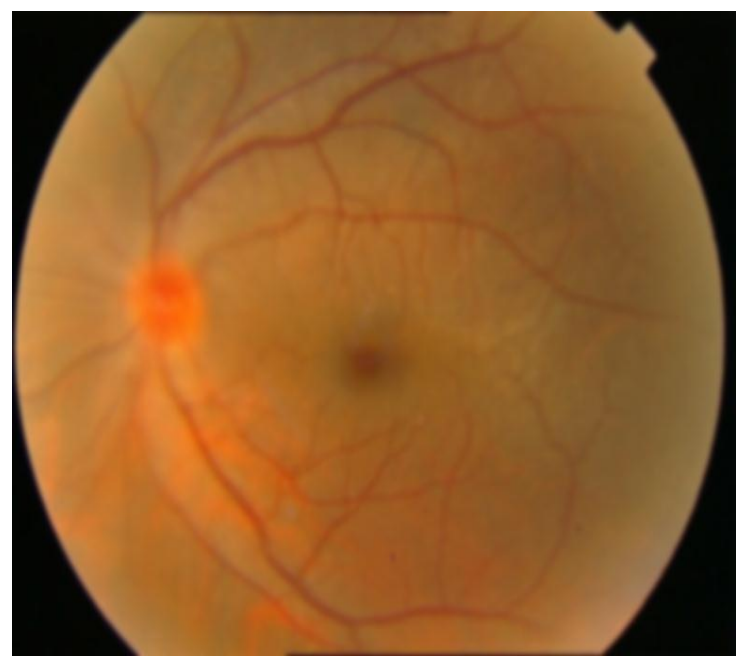

Figure 8-6 (A).Colored fundus photography showing left hyperemic disc

\section{Discussion}

Interferon associated retinopathy was first recognized in 1990 when Ikebe and associates reported a 39-year-old patient who developed retinal hemorrhages and cotton wool spots following intravenous administration of Interferon. The exact mechanism of interferoninduced-retinopathy is not known but is presumably related to the disturbance in retinal microcirculation [10]. The deposition of immune complexes in vessels, immunological dysfunction, endothelial dysfunction, and increased adhesion of activated leukocytes to vascular walls has also been suggested [11]. These deposits and adhesions cause retinal ischemia with resultant capillary non-perfusion and nerve fiber layer infarctions [12].

A major advance in treating hepatitis $\mathrm{C}$ virus patients has developed world wide since January 2001, with the approval of pegylated interferon alpha in U.S.A by the food and drug administration. The currently recommended therapy in treating chronic hepatitis $\mathrm{C}$ virus patients nowadays is a combination of PegIFNalpha-2a (Pegasys in U.S.A, Reiferon Retardin Egypt), and the broad spectrum antiviral agent Ribavirin. These pegylated drugs are injected once weekly, rather than administering three times per week [13].

Most of the ocular side effects occuring during IFN-alpha treatment are benign, transient and are mainly represented by the classical "specific" IFN-related retinopathy. Retinopathies related to interferon are charecterized by cotton wool spots, retinal hemorrhages, capillary non-perfusion, vasospasm, arteriolar occlusion and microaneurysms; at the posterior fundus, particularly around the optic disc [14].

The incidence of retinopathy associated with interferon treatment varies in literature from 18 $86 \%$ [15]. The frequencies of interferon related retinopathy associated with IFN monotherapy and IFN-Ribavirin combination therapy are reported in literature to be $16-64 \%$ studied by 
Cuthbertson and coworkers in 2004, and 19\% to $69 \%$ by Narkewicz and co-workers in 2010.

In our study, retinopathy in the form of cotton wool spots was the main complication of interferon/ribavirin therapy; other than dry eye, which was observed in almost all of the patients. Interferon retinopathy in the form of retinal hemorrhages didn't develop in any case throughout the interferon therapy course.

Cotton wool spots developed in 16 cases $(16 \%)$.In all the cases, the visual acuity was not affected and the spots were away from the macula. In our study the patients' ages varied from 21 to 60 years old. Patients who developed retinopathy, their age ranged from 33 to 60 years old with mean \pm SD of $46.7 \pm 7.8$. The age was statistically significant with a $p$ value of 0.041 ( less than 0.05). This significance correlates with the conclusion of a previous study that mentioned the age as a risk factor of interferon retinopathy [16].

A previous study reported that INF retinopathy can occur between the $4^{\text {th }}$ and $28^{\text {th }}$ weeks after initiation of treatment, more frequently within the first 16 weeks [17]. The incidence is possibly influenced by the frequency of fundus examination, because the subtle retinopathy may disappear after the long intervals between examinations.

In our study the cotton wool spots developed in all the patients within the $12^{\text {th }}$ week and the $24^{\text {th }}$ week with an average of week $16^{\text {th }}$. Cotton wool spots decreased in 6 patients $(6 \%)$, disappeared in $3(6 \%)$ and lasted in 4 patients (4\%), at the end of 48 weeks. So, retinopathy may disappear spontaneously during therapy or rapidly after stopping therapy with continuation of full-dose of IFN treatment. All the patients with cotton wool spots continued the course of therapy without any affection of the visual acuity, except a patient who discontinued therapy after 24 weeks due to decrease of all his blood parameters without improvement of the virology level.

In our study, 6\% developed cotton wool spots, chronic hepatitis $\mathrm{C}$ was the only systemic illness. Among the group, 6\% had low hemoglobin level $\leq 9 \mathrm{mg} / \mathrm{dl}$, only $2 \%$ developed unilateral cotton wool spot. In a study done to measure the retinal blood flow, anemia was mentioned as a risk factor for retinopathy when the hemoglobin decreases to 6 to $7 \mathrm{mg} / \mathrm{dL}$ [12].

The hemoglobin level of the patient who developed cotton wool spot in our study is slightly higher than the level mentioned in the literature and was statistically insignificant with a $p$ value 0.071 (more than 0.05). Further studies are needed to detect whether or not anemia is a risk factor for interferon retinopathy. The remaining $4 \%$ developed other complications in the form of maculopathy (2\%) and glaucomatous cupping and field defect (2\%). According to the interferon retinopathy mechanism mentioned in our discussion, 
deposition of immune complex within the vessel wall and microcirculatory affection may explain the pathogenesis of retinopathy in this patient, although further studies are needed. Tobacco Smoking has not proven any significance as a risk factor of interferon retinopathy, in the study done by Nishiguchi and co-workers in 2001 as well as in our study.

In our study, laboratory investigations revealed that there was no significant difference ( $p$ value $\geq 0.05$ ) between patients with and without retinopathy; regarding the albumin level, platelet count and prothrombin concentration. Unfortunately, routine lipid profile was not done to our patients to detect the level of triglycerides and dyslipidemia. Further studies are needed with routine lipid profile to detect its association with interferon retinopathy and if its relation to arteriosclerosis that was suggested by Okuse and co-workers in 2006 as one of the pathogenesis of retinopathy that affects the microcirculation. The incidence of retinopathy is thought to depend on the initial dose of INF-alpha and patients receiving high dosages such as $9 \times 10^{6} \mathrm{IU} /$ day, 6 days per week, are usually at increased risk of retinopathy [18]. In our study the dose and regimen of interferon was the same in the study group, so to detect whether or not the dose of interferon leads to retinopathy couldn't be concluded from our study.
In our study in addition to retinopathy, we reported a case of bilateral disc edema in a 30 years old male patient with no medical disease other than HVC and no special habits of medical importance. The patient's BCVA 6/36(OD) and 6/24(OS).

In the literature; Foroozan, in 2004 reported a case of optic disc edema in a 32 years old female and he suggested that the disc appeared more ischemic due to the superimposed anemia as hepatitis $\mathrm{C}$ treated with INF $\alpha$ and ribavirin has been associated with anemia. Six of the eight prior reports describing optic disc swelling related to INF alpha noted that the complete blood count was normal[19].

In our study we reported four cases developed maculopathy within the course of the disease. It appeared by bimicroscopy examination and FFA couldn't detect any abnormality. The maculopathy appeared in the form of mottling without affecting the patients' vision.

In the study we reported a case complained of musca and floaters by the $12^{\text {th }}$ week of the interferon course. After examination it was found that the patient developed posterior vitreous detachment (PVD). The patient was advised to undergo regular ophthalmological follow up. PVD wasn't mentioned in the literature as a side effect of interferon, although retinal detachment was reported in small number [20]. In further studies retinal 
detachment was mentioned as a coincidence rather than a true association with interferon use [21].

Last reported case was a female 29 years old developed glaucomatous optic cupping and bilateral enlargement of the blind spot reported by field perimetry by the $8-12$ weeks. The C/D ratio was 0.5 bilateral and $\mathrm{BCVA}$ was $6 / 9(\mathrm{OD})$, 6/12 (OS). The patient's IOP (intra ocular pressure) was controlled on topical antiglaucoma medication and it returned to normal after ending the interferon course. Young-Se and co-workers, reported a case of glaucoma that appeared after initiation of interferon alpha therapy and disappeared after one month of discontinuation of the drug therapy [22].

Fortunately, in our study none of the patients developed diminution of vision through the interferon course and most of the cases were reversible once treatment is stopped and sometimes even improved, despite the continuation of therapy. Interferon associated retinopathy was first recognized in 1990 when Ikebe and associates reported a 39-year-old patient who developed retinal hemorrhages and cotton wool spots following intravenous administration of Interferon.

The exact mechanism of interferon-inducedretinopathy is not known but is presumably related to the disturbance in retinal microcirculation [21]. The deposition of immune complexes in vessels, immunological dysfunction, endothelial dysfunction, and increased adhesion of activated leukocytes to vascular walls has also been suggested. These deposits and adhesions cause retinal ischemia with resultant capillary non-perfusion and nerve fiber layer infarctions [23].

A major advance in treating hepatitis $\mathrm{C}$ virus patients has developed world wide since January 2001, with the approval of pegylated interferon alpha in U.S.A by the food and drug administration. The currently recommended therapy in treating chronic hepatitis $\mathrm{C}$ virus patients nowadays is a combination of PegIFNalpha-2a (Pegasys in U.S.A, Reiferon Retardin Egypt), and the broad spectrum antiviral agent Ribavirin. These pegylated drugs are injected once weekly, rather than administering three times per week [24].

Most of the ocular side effects occurring during IFN-alpha treatment are benign, transient and are mainly represented by the classical "specific" IFN-related retinopathy. Retinopathies related to interferon are characterized by cotton wool spots, retinal hemorrhages, capillary non-perfusion, vasospasm, arteriolar occlusion and microaneurysms; at the posterior fundus, particularly around the optic disc [25].

The incidence of retinopathy associated with interferon treatment varies in literature from 18$86 \%$ [26]. The frequencies of interferon related retinopathy associated with IFN monotherapy 
and IFN-Ribavirin combination therapy are reported in literature to be $16-64 \%$ studied by Cuthbertson and coworkers in 2004, and $19 \%$ to $69 \%$ by Narkewicz and co-workers in 2010.

In our study, retinopathy in the form of cotton wool spots was the main complication of interferon/ribavirin therapy; other than dry eye, which was observed in almost all of the patients. Interferon retinopathy in the form of retinal hemorrhages didn't develop in any case throughout the interferon therapy course.

Cotton wool spots developed in 16 cases (16\%).In all the cases, the visual acuity was not affected and the spots were away from the macula. In our study the patients' ages varied from 21 to 60 years old. Patients who developed retinopathy, their age ranged from 33 to 60 years old with mean \pm SD of $46.7 \pm 7.8$. The age was statistically significant with a $p$ value of 0.041 (less than 0.05). This significance correlates with the conclusion of a previous study that mentioned the age as a risk factor of interferon retinopathy [21].

A previous study reported that INF retinopathy can occur between the 4th and 28th weeks after initiation of treatment, more frequently within the first 16 weeks [27]. The incidence is possibly influenced by the frequency of fundus examination, because the subtle retinopathy may disappear after the long intervals between examinations.
In our study the cotton wool spots developed in all the patients within the 12th week and the 24 th week with an average of week 16th. Cotton wool spots decreased in 6 patients (6\%), disappeared in 3(6\%) and lasted in 4 patients (4\%), at the end of 48 weeks. So, retinopathy may disappear spontaneously during therapy or rapidly after stopping therapy with continuation of full-dose of IFN treatment. All the patients with cotton wool spots continued the course of therapy without any affection of the visual acuity, except a patient who discontinued therapy after 24 weeks due to decrease of all his blood parameters without improvement of the virology level.

In our study, 6\% developed cotton wool spots, chronic hepatitis $\mathrm{C}$ was the only systemic illness. The remaining 4\% developed other complications in the form of maculopathy $(2 \%)$ and glaucomatous cupping and field defect $(2 \%)$

According to the interferon retinopathy mechanism mentioned in our discussion, deposition of immune complex within the vessel wall and microcirculatory affection may explain the pathogenesis of retinopathy in this patient, although further studies are needed.

Tobacco Smoking has not proven any significance as a risk factor of interferon retinopathy, in the study done by Nishiguchi and co-workers in 2001 as well as in our study. 
The incidence of retinopathy is thought to depend on the initial dose of INF-alpha and patients receiving high dosages such as 9106 IU/day, 6 days per week, are usually at increased risk of retinopathy [28]. In our study the dose and regimen of interferon was the same in the study group, so to detect whether or not the dose of interferon leads to retinopathy couldn't be concluded from our study.

In our study in addition to retinopathy, we reported a case of bilateral disc edema in a 30 years old male patient with no medical disease other than HVC and no special habits of medical importance. The patient's BCVA 6/36(OD) and 6/24(OS).

In our study we reported four cases developed maculopathy within the course of the disease. It appeared by bimicroscopy examination and FFA couldn't detect any abnormality. The maculopathy appeared in the form of mottling without affecting the patients' vision.

In our study we reported a case complained of musca and floaters by the 12th week of the interferon course. After examination it was found that the patient developed posterior vitreous detachment (PVD). The patient was advised to undergo regular ophthalmological follow up. PVD wasn't mentioned in the literature as a side effect of interferon, although retinal detachment was reported in small number [29]. In further studies retinal detachment was mentioned as a coincidence rather than a true association with interferon use [30]. Last reported case was a female 29 years old developed glaucomatous optic cupping and bilateral enlargement of the blind spot reported by field perimetry by the $8-12$ weeks. The C/D ratio was 0.5 bilateral and BCVA was 6/9 (OD), 6/12 (OS).

Fortunately, in our study none of the patients developed diminution of vision through the interferon course and most of the cases were reversible once treatment is stopped and sometimes even improved, despite the continuation of therapy.

\section{Conclusion and Recommendations}

We reported the incidence of retinopathy related to peginterferon alpha and ribavirin combination therapy in chronic hepatitis $\mathrm{C}$ virus patients. The retinopathy developed in average of 16 weeks after the start of therapy. Retinopathy develops in the form of cotton wool spots. The retinopathy disappeared spontaneously during therapy or rapidly after stopping the therapy. Despite the retinopathy, most patients have had good visual acuity.

\section{References}

1. Abe T, Nakajima A, Satoh N, Koizumi T, Sakuragi S, Ono T, Komatsu $\mathrm{M}$ and Masamune O. Clinical characteristics of hepatitis $\mathrm{C}$ virus-associated retinopathy. Jpn J Clin Ophthalmol (Rinsho Ganka), 1995; 39: 411-419. 
2. Abe $\mathrm{T}$, Sakuragi $\mathrm{S}$ and Kuramitsu $\mathrm{T}$. Retinopathy associated with hepatitis C virus. Jpn J Clin Ophthalmol (Rinsho Ganka), 1993; 47: 297-300.

3. Alcami A, Symons JA. and Smith GL. The vaccinia virus soluble alpha/beta interferon (IFN) receptor binds to the cell surface and protects cells from the antiviral effects of IFN. J Virol, 2000; 74: 11230-11239.

4. Bach EA, Aguet $M$ and Schreiber RD. The IFN gamma receptor: a paradigm for cytokine receptor signaling. Annu Rev Immunol., 1997; 15: 563-591.

5. Bajaire BJ, Paipilla DF, Arrieta CE and Oudovitchenko E. Mixed vascular occlusion in a patient with interferonassociated retinopathy. Case Report Ophthalmol., 2011; 2: 23-29.

6. d'Alteroche L, Majzoub S, Lecuyer AI, Delplace MP and Bacq Y. Ophthalmologic side effects during alphainterferon therapy for viral hepatitis. J Hepatol., 2006; 44: 56-61.

7. Damien $\mathrm{S}$, Valérie $\mathrm{T}$ and Bahram $\mathrm{B}$. Intraocular complications of IFN- $\alpha$ and ribavirin therapy in patients with chronic viral hepatitisC. World J Gastroenterol., 2007; 13: 3137-31.

8. Foster GR. Pegylated interferons for the treatment of chronic hepatitis $\mathrm{C}$ : pharmacological and clinical differences between peginterferon-alpha-2a and peginterferon-alpha-2b. Drugs, 2010; 70: 147-165.

9. Fried MW, Shiffman ML, Reddy KR, Smith C, Marinos G, Goncales FL, Jr., Haussinger D, Diago M, Carosi G, Dhumeaux D, Craxi A, Lin A, Hoffman J and $\mathrm{Yu}$ J. Peginterferon alfa-2a plus ribavirin for chronic hepatitis $\mathrm{C}$ virus infection. N Engl J Med., 2002; 347: 975982.

10. Gillies M, Francis I, McCluskey P and Wakefield D. Local interferon alfa-2b for ocular cicatricial pemphigoid. $\mathrm{Br} \quad \mathrm{J}$ Ophthalmol., 1996; 80: 927.

11. Gonçalves LL, Farias AQ, Gonçalves PL, D'Amico EA and Carrilho FJ. Branch retinal vein thrombosis and visual loss probably associated with pegylated interferon therapy of chronic hepatitis C (case report). World J Gastroenterol., 2006; 12: 4602-4603.

12. Guyer DR, Tiedeman J, Yannuzzi LA, Slakter JS, Parke D, Kelley J, Tang RA, Marmor M, Abrams G, Miller JW, et al. Interferon-associated retinopathy. Arch Ophthalmol., 1993; 111: 350-356.

13. Hayasaka S, Nagaki Y, Matsumoto M and Sato S. Interferon associated retinopathy. Br J Ophthalmol., 1998; 82: 323-325.

14. Hoofnagle JH, Di Bisceglie AM, Waggoner JG and Park Y. Interferon alfa 
for patients with clinically apparent cirrhosis due to chronic hepatitis B. Gastroenterology., 1993; 104(4): 1116-21.

15. Jain K, Lam WC, Waheeb S, Thai Q and Heathcote J. Retinopathy in chronic hepatitis $\mathrm{C}$ patients during interferon treatment with ribavirin. $\mathrm{Br} \quad \mathrm{J}$ Ophthalmol., 2001; 85: 1171-1173.

16. Junaid $\mathrm{S}$, Jacinthe $\mathrm{R}$ and Andrew $\mathrm{G}$. Bilateral Optic Neuritis in Acute Hepatitis C. Journal of Neuro-Ophthalmology, 2009; 29: 128-133.

17. Kabbaj N, Sentissi S, Mohammadi M, Benaissa A and Amrani N. Anterior ischemic optic neuropathy complicating interferon alpha and ribavirin therapy in patients with chronic hepatitisC. Gastroenterol Clin Biol., 2009; 33: 115117.

18. Kawano T, Shigehira M, Uto H, Nakama T, Kato J, Hayashi K, Maruyama T, Kuribayashi T, Chuman T, Futami T and Tsubouchi H. Retinal complications during interferon therapy for chronic hepatitis C. Am J Gastroenterol., 1996; 91: 309-313.

19. Nagaoka T, Sato E, Takahashi A, Yokohama S and Yoshida A. Retinal circulatory changes associated with interferon-induced retinopathy in patients with hepatitis C. Invest Ophthalmol Vis Sci., 2007; 48: 368-375.
20. Nocente R, Ceccanti M, Bertazzoni G, Cammarota G, Silveri NG and Gasbarrini G. HCV infection and extrahepatic manifestations. Hepatogastroenterology, 2003; 50: 1149-1154.

21. Norcia F, Di Maria A, Prandini F and Redaelli C. Natural interferon therapy: optic nerve ischemic damage? Ophthalmologica, 1999; 213: 339-340.

22. Okanoue T, Sakamoto S, Itoh Y, Minami M, Yasui K, Sakamoto $M$ et al. Side effects of high-dose interferon therapy for chronic hepatitis C. J Hepatol., 1996; 25(3): 283-91.

23. Okuse C, Yotsuyanagi H, Nagase $\mathrm{Y}$, Kobayashi Y, Yasuda K, Koike K, Iino S, Suzuki $M$ and Itoh F. Risk factors for retinopathy associated with interferon alpha-2b and ribavirin combination therapy in patients with chronic hepatitis C. World J Gastroenterol., 2006; 12: 3756-3759.

24. Reichard O, Schvarcz R and Weiland O. Therapy of hepatitis $\mathrm{C}$ : alpha interferon and ribavirin. Hepatology, 1997; 26: 108S-111S

25. Rosen HR. Clinical practice. Chronic hepatitis C infection. N Engl J Med., 2011; 364: 2429-2438.

26. Savant $\mathrm{V}$ and Gillow $\mathrm{T}$. Interferonassociated retinopathy. Eye (Lond), 2003; 17: 534-536. 
27. Seddik H, Tamzaourte M, Rouibaa F, 29. Sheth HG, Michaelides M and Fadlouallah $\mathrm{M}$ and Benkirane $\mathrm{A}$. Siriwardena D. Cystoid macular edema Irreversible anterior ischemic optic and visual loss as sequelae to interferon neuropathy complicating interferon alpha alpha treatment of systemic hepatitis C. and ribaverin therapy. Int $\mathbf{J}$ Hepatol., Indian J Ophthalmol., 2010; 58: 147-148. 2011; 2011: 814242.

30. Tokai R, Ikeda T, Miyaura T and Sato K.

28. Sharieff KA, Duncan D and Younossi Z. Advances in treatment of chronic hepatitis Interferon-associated retinopathy and cystoid macular edema. Arch C: 'pegylated' interferons. Cleve Clin J Ophthalmol., 2001; 119: 1077-1079. Med., 2002; 69: 155-159. 